CLINICAL STUDY

\title{
Reference intervals in evaluation of maternal thyroid function during the first trimester of pregnancy
}

\author{
Drahomira Springer, Tomas Zima and Zdena Limanova ${ }^{1}$ \\ Department of Clinical Biochemistry and Laboratory Medicine, General Teaching Hospital, First Faculty of Medicine Charles University, U Nemocnice 2, \\ 12000 Prague, Czech Republic and ${ }^{1}$ 3rd Medical Department, Clinical Department of Endocrinology and Metabolism, General Teaching Hospital, First \\ Faculty of Medicine Charles University, 120 O0 Prague, Czech Republic \\ (Correspondence should be addressed to D Springer; Email: springer@vfn.cz)
}

\begin{abstract}
Background: Insufficient function of the thyroid gland can cause low concentrations of thyroid gland hormones which are necessary for the proper development of the foetus brain, especially during the beginning of pregnancy. We determined the reference interval for TSH in the first trimester of pregnancy and the decision point for anti-TPO antibodies' positivity.

Methods: We tested 5520 women from the central part of the Czech Republic during the first trimester of pregnancy for serum TSH, anti-TPO and FT4 by chemiluminometric immunoanalysis on an ADVIA Centaur system (Siemens). The reference interval for TSH during the first trimester of pregnancy was determined using the log transformation, and then summarized as the geometrical mean (95\% CI); following which, a suitable decision point for anti-TPO positivity was set.

Results: The reference interval for TSH was determined to be 0.06-3.67 mU/l. The suppression of TSH was found in $2.93 \%$ of the women; a raised concentration of TSH had been found in $4.48 \%$ of the women. For anti-TPO, the cut-off was established at $143 \mathrm{kU} / \mathrm{l} ; 11.2 \%$ of the pregnant women were found to be anti-TPO positive.

Conclusion: Determination of the reference interval for TSH during early pregnancy is one of the basic requirements when implementing a general examination of the thyroid gland at the beginning of pregnancy. The decision level for positivity of anti-TPO is more than double the manufacturer's reference interval.
\end{abstract}

European Journal of Endocrinology 160 791-797

\section{Introduction}

Many changes in the functioning of the thyroid gland occur during pregnancy and some diseases of the thyroid gland can affect both the pregnant woman and the foetus. Hypothyroidism is the most serious disorder of those occurring during pregnancy, and it might go unnoticed as some 'non-specific' problem. The implications are staggering when one considers that there is a significant increase in intrauterine deaths, spontaneous abortions, premature births and preeclampsia (1-4); as well as problems in the development of the foetus, such as major malformations and decrease in IQ (5-8). While the hyperfunction during pregnancy usually manifests itself in clinical symptoms or a relapse of a previously cured disease (mostly Graves-Basedow (9)), lowered function is much more dangerous because of its non-specific symptoms. It has been clearly proven that even mild (subclinical) hypothyroidism affects not only the course of pregnancy $(1,4)$, but also (especially later on) the neuropsychological development of the child (10-12). Symptoms of hypothyroidism (fatigue, lowered performance, sleepiness, psychological lability) can also accompany the physiological pregnancy; some women with subclinical hypothyroidism are absolutely asymptomatic (9).

Results of general population screenings vary slightly, depending upon the level of medical care and the approach to prevention, geographical conditions, supplementation with iodine $(3,9,13)$, as well as other circumstances (including used diagnostic criteria). Evaluating thyroidal function during pregnancy is difficult considering the other differing influences of pregnancy (14).

Determining TSH in the serum is a basic search procedure in the diagnosis of the thyroid gland's function. Its regulation is based on feedback, however, during pregnancy there are also other mechanisms taking place (mainly suppression of TSH) presumably due to the thyroid-stimulating activity of hCG early in pregnancy when hCG levels are the highest (15).

By using the classic reference interval for serum TSH, one might misdiagnose as healthy women who already have a slight TSH elevation and, conversely, one might suspect hyperthyroidism in normal women who have a lowered serum TSH value (16). 
Determining the reference interval suitable for the first trimester of pregnancy is possible by using the suggestion of the National Academy of Clinical Biochemistry (NACB) on selected samples from the population, or as the 95 th percentile from the cohort of women (17).

Determination of FT4 is by watching the amount of biologically active hormone which is available to the organism of a pregnant woman (as well as the foetus), and is not affected by the concentration of binding proteins. Its concentration during pregnancy is partly affected by both the inflow of iodine and the duration of the pregnancy. Some consider it even more informative than TSH during pregnancy (2). The foetus is completely dependent upon thyroxin produced by the mother during the first trimester. Even a small unnoticed malfunction of the mother's thyroid gland, which doesn't necessarily endanger the course of the pregnancy, can affect the psychomotor development of the child (10).

Anti-TPO antibodies are markers of autoimmune process in the thyroid gland, and their determination is diagnostically and prognostically important $(18,19)$. The presence of anti-TPO during pregnancy also alerts one to the danger of the development of post partum thyreoiditidis (20); about $50 \%$ of anti-TPO positive women have some thyroid dysfunction after delivery $(19,20)$, so follow-up of these women is necessary.

Malfunction of the thyroid gland during pregnancy is long-term, and still not a problem sufficiently resolved. There are even now new arguments for systematic screening of pregnant women for thyroid underfunction and asymptomatic chronic thyroiditis, in order to give such women the appropriate treatment (21). This study is another 'vote' for the screening of thyroid dysfunction during pregnancy.

The aim of this study was the determination of the reference intervals for TSH in the first trimester of pregnancy, and the cut-off for anti-TPO. After that, with these intervals, the aim was to find the percentage of thyroid dysfunction in the population of pregnant women in the central portion of the Czech Republic. Iodized salt has been in regular use there since the 1950 s, and a good level of iodine supplementation can be expected also based on the study by Zamrazil (22). We just do not know the exact iodine status of this study group.

\section{Materials and methods}

\section{Samples}

The study group (nonselected, NS) consisted of 5520 pregnant women (in their 9-11th week of pregnancy, 99\% Caucasian) who were undergoing their first trimester prenatal screening in the Institute of Clinical Biochemistry and Laboratory Diagnostics of Charles University, Prague, Czech Republic. Blood samples were collected and centrifuged for $10 \mathrm{~min}$ after temperature reduction and formation of the clot. Subsequently, the serum was removed and free $\beta$ hCG was determined within $4 \mathrm{~h}$. Pregnant women (with informed consent) were serum assayed for TSH and anti-TPO. FT4 $(n=697)$ was determined only in the case of TSH or anti-TPO out of the reference interval.

For evaluation of the reference interval, a selected group (S1) was created in accordance with the recommendations of the NACB. From the group of pregnant women, all those with a history of thyroid disease were excluded; anti-TPO $>60 \mathrm{kU} / \mathrm{l}$ (the manufacturer's cut-off) and free $\beta$ hCG higher than triple of the median $(56.6 \mu \mathrm{g} / \mathrm{l})$, in view of the suppression of TSH by a high level of hCG were also excluded. We could not meet the other recommendation of the NACB (a family history of thyroid disease for the selection of women), as we did not have access to this data.

For the determination of pregnancy cut-off for antiTPO, a selected group (S2) was created. From all the women, women with a known history of thyroid disease were separated, as well as those with TSH lower than 0.1 and higher than $4.0 \mathrm{mU} / \mathrm{l}$. This interval had been used earlier by us for the evaluation of positive results in pregnancy; it was deduced from both specialized literature and our own experience.

The control group (C) for the evaluation of mean age was created by using pregnant women with TSH between 0.06-3.67 mU/l (our new reference interval) and with anti-TPO under the manufacturer's reference interval of $60 \mathrm{kU} / \mathrm{l}$.

\section{Methods}

TSH, anti-TPO and FT4 were assayed by ADVIA Centaur (Siemens, Healthcare Diagnostics Inc, Tarrytown, NY, USA), with chemiluminometric detection. TSH was determined by sandwich immunoanalysis with direct chemiluminometric technology; for anti-TPO and FT4 competitive immunoanalysis, direct chemiluminometric technology was also used.

Reproducibility of this method is expressed by the interassay variability. For TSH, it is $5-7 \%$ for levels of $0.43-15.00 \mathrm{mU} / \mathrm{l}$; for anti-TPO it is $10 \%$ for the level of $70 \mathrm{kU} / \mathrm{l}$ and $7 \%$ for the level of $170 \mathrm{kU} / \mathrm{l}$. Interassay variability for FT4 is $7-9 \%$ for levels between 10.1-33.0 pmol/l.

Free $\beta$ hCG was assayed on a BRAHMS KRYPTOR. This system uses the time resolved amplified cryptate emission technology, based upon a non-radiative transfer of energy. Interassay variability for free $\beta$ hCG is $3.0 \%$.

\section{Statistic analysis}

The statistical analysis was performed using Statistica 7.1 CZ software (StatSoft, Prague 6, Czech Republic). All values are reported as mean \pm s.D. or as shift percentages. 
TSH and anti-TPO do not follow a normal distribution; they have to be normalized using log transformation. The reference interval was then determined using this log transformed data and geometric means are used to describe the means.

One-way ANOVA and post hoc P-levels for the Tukey honest significant difference (HSD) were considered to be statistically significant at the $P<0.05$ level.

\section{Results}

\section{Reference interval for TSH in pregnancy}

The NS, as well as the selected group S1, were statistically analyzed and results are shown in Table 1.

Evaluation of positive results for the reference interval created at the $2.5,5,95$ and 97.5th percentile of the selected group (S1) are presented in Table 2.

We selected an acceptable reference interval for TSH in pregnant women such as the 2.5 th percentile for the lower, and 97.5 th percentile of the selected group S1 $(0.06-3.67 \mathrm{mU} / \mathrm{l})$. We found a very similar upper limit by using the 95 th percentile of the NS (3.71 mU/l). In our group of pregnant women, $2.93 \%$ had a low level of TSH, while $4.48 \%$ had TSH over the reference interval.

\section{Decision value for positivity of anti-TPO in pregnancy}

The selected group (S2) and the NS were both statistically analyzed, all the results are shown in Table 3.

The decision limit for a recommendation to visit an endocrinologist was determined to be $143 \mathrm{kU} / \mathrm{l}$ antiTPO. The manufacturer's cut-off $(60 \mathrm{kU} / \mathrm{l})$ and our interval (the 90th percentile of the selected group S2) were both used for an evaluation of positivity for anti-TPO.

Using the manufacturer's cut-off level we found $22.1 \%$ of the women to be with positive anti-TPO antibodies; using our decision value $(143 \mathrm{kU} / \mathrm{l})$, it was $11.2 \%$.

\section{Evaluation of FT4 levels in pregnancy}

FT4 was determined only for women $(n=697)$ with TSH lower than 0.1, and higher than $4.00 \mathrm{mU} / \mathrm{l}$ or antiTPO higher than $60 \mathrm{kU} / \mathrm{l}$. For FT4, we used the manufacturer's reference interval of 9.8-23.1 pmol/l for all populations. The use of the 2.5th and 97.5th percentile for the calculation of the reference interval in the NS gave us our reference interval (9.55$23.0 \mathrm{pmol} / \mathrm{l}$ ) - almost identical to the manufacturer's.

There were $30(4.3 \%)$ women with FT4 under and 18 $(2.5 \%)$ women with FT4 over the reference interval. In women with low FT4, 62.7\% were with positive antiTPO antibodies.

\section{Suppression of TSH level by high hCG}

The mean free $\beta$ hCG of women with suppressed TSH is double, in comparison with the group with a normal or higher TSH. One-way ANOVA test at the $P<0.05$ level was statistically significant for differences between the mean of free $\beta$ hCG for groups with different TSH levels. The posthoc analysis by application of the Tukey HSD test showed statistical significant differences between means of free $\beta$ hCG in the group with low TSH $(<0.06 \mathrm{mU} / \mathrm{l})$, and in groups with normal or higher TSH. The results of the statistical analysis are shown in Table 4.

On the other hand, differences between groups with normal and higher TSH are not statistically significant.

\section{High level TSH and anti-TPO antibodies positivity}

Higher TSH is also very often associated with positivity of anti-TPO antibodies. In the group with TSH $>3.67 \mathrm{mU} / \mathrm{l}$, there were $44.1 \%$ of women with antibody positivity (anti-TPO >143 kU/l); and in groups with $\mathrm{TSH}<0.06 \mathrm{mU} / \mathrm{l}$ or in the pregnancy reference interval only $10.1 \%$ or $9.1 \%$ of the women had antibody positivity. A one-way ANOVA test at the $P<0.05$ level was statistically significant for differences between the levels of anti-TPO for groups with different TSH levels. The level of anti-TPO in the group with higher TSH is significantly higher at $P<0.050$; differences between groups with low or normal TSH are not statistically significant.

\section{The influence of age over anti-TPO antibodies positivity and high TSH}

The average age in the NS was $31.3( \pm 4.6)$, in the control group (C) of pregnant women it was 31.2 $( \pm 4.3)$ years. One-way ANOVA analysis confirmed no statistically significant differences in the average age, at

Table 1 Reference ranges of TSH in pregnancy for non-selected (NS) and selected (S1) groups of pregnant women.

\begin{tabular}{lcccccccc}
\hline TSH $\mathbf{~ m U / l}$ & $\mathbf{N}$ & Median & Minimum & Maximum & $\begin{array}{c}\text { 2.5th } \\
\text { percentile }\end{array}$ & $\begin{array}{c}\text { 5th } \\
\text { percentile }\end{array}$ & $\begin{array}{c}\text { 95th } \\
\text { percentile }\end{array}$ & $\begin{array}{c}\text { 97.5th } \\
\text { percentile }\end{array}$ \\
\hline NS & 5520 & 1.280 & 0 & 411.874 & 0.048 & 0.147 & 3.713 & 4.796 \\
S1 & 4337 & 1.213 & 0 & 11.534 & 0.062 & 0.154 & 3.144 & 3.670 \\
\hline
\end{tabular}

$\mathrm{S} 1$, pregnant women with no history of thyroid disease, anti-TPO level lower than $60 \mathrm{kU} / \mathrm{l}$ and free $\beta \mathrm{hCG}$ lower than triple that of the median $(56.6 \mu \mathrm{g} / \mathrm{l})$. 
Table 2 Distribution of TSH in groups of women in the first trimester of pregnancy by different reference range (percentile of selected group S1).

\begin{tabular}{lccc}
\hline & TSH mU/l & N & Percent \\
\hline <2.5th percentile & $<0.062$ & 163 & 2.93 \\
<5th percentile & $<0.154$ & 288 & 3.18 \\
> 95th percentile & $>3.144$ & 458 & 8.24 \\
> 97.5th percentile & $>3.670$ & 249 & 4.48 \\
\hline
\end{tabular}

S1, pregnant women with no history of thyroid disease, anti-TPO level lower than $60 \mathrm{kU} / \mathrm{l}$ and free $\beta \mathrm{hCG}$ lower than triple that of the median $(56.6 \mu \mathrm{g} / \mathrm{l})$.

the $P<0.05$ level, between groups with different TSH and anti-TPO levels.

The entire NS was divided into separate subgroups by age, and then the Tukey test was applied for determination of the statistical significance of differences with TSH and antiTPO levels. There was no significant trend $(P<0.05)$ for TSH or anti-TPO levels to rise with increasing age in the women.

Determination of reference intervals for $\mathrm{TSH}$ $(0.06-3.67 \mathrm{mU} / \mathrm{l})$, anti-TPO $(<143 \mathrm{kU} / \mathrm{l})$ and FT4 $(9.8-23.0 \mathrm{pmol} / \mathrm{l})$ in the first trimester is the starting step for screening of thyroid disease in pregnancy. A suitable method for the calculation of a reference interval was tested on a group of 5520 pregnant women. Of the women $2.93 \%$ were with low and $4.5 \%$ with high TSH. The positivity of anti-TPO antibodies in all of them was $11.2 \%$.

\section{Discussion}

Questions regarding thyroid disease and pregnancy have very often been discussed in recent years, and clinical guidelines often pay attention to this problem. Prior to the introduction of screening for thyroid dysfunction in early pregnancy, it is necessary to establish specific reference intervals for TSH, FT4 and anti-TPO. In older references, the reference interval is often designated as the reference range. For the determination of reference intervals, various methods have been used $(23,24)$. For TSH, Haddow (2004) used the 98th percentile in the entire group of anti-TPO negative woman (25). Vaidya (2006) used a reference interval based on the squared $95 \%$ confidence intervals in anti-TPO negative woman for TSH and FT4 (26). FT4 has a normal distribution of data, so it is possible to use mean \pm s.D., median and the 2.5th and 97.5th percentiles. TSH and anti-TPO have to be normalized using log transformation, as they do not follow a normal distribution. The NACB guidelines (17) are commonly used, and TSH reference intervals are established from the $95 \%$ confidence limits of the log-transformed values of anti-TPO Ab negative, ambulatory euthyroid subjects, who have no personal or family history of thyroid dysfunction and no visible goitre (27). The manufacturer's reference interval for our method (ADVIA Centaur, Siemens) is $0.37-5.00 \mathrm{mU} / \mathrm{l}$. The reference interval was calculated for the 2.5, 5, 95 and 97.5th percentiles for TSH. For the first trimester, the specific reference interval we used were the 2.5th and 97.5th percentiles of the selected group S1, without anti-TPO $\mathrm{Ab}$ positive women and woman with hCG $>$ triple that of the median. Our reference intervals for TSH were established upon 0.062-3.67 mU/l. When we used the 95th percentile for evaluation in the group of nonselected samples, the upper limit was $3.71 \mathrm{mU} / \mathrm{l}$. Vaidya (2006) calculated for the TSH their own reference interval of $0.09-3.03 \mathrm{mU} / \mathrm{l}$, in comparison with the manufacturer's value of $0.27-4.20 \mathrm{mU} / \mathrm{l}$ (26). Other authors apply either the manufacturer's $(13,25)$ or their own reference intervals $(26,27)$ for TSH (which vary from 2.0 to $5.0 \mathrm{mU} / \mathrm{l}(17)$ ). Some authors established trimester-specific reference intervals for pregnant women (28-30). All of these confirmed a lower TSH level in the first trimester, which is important for selection of those women at risk of thyroid dysfunction, and hence appropriate for endocrinology consultation.

Lower serum TSH is influenced by the thyrotropic activity of elevated circulating human chorionic gonadotropin concentrations, mainly in the first trimester $(9,31)$. In our group of pregnant women, with suppressed TSH, the average level of hCG was almost double $(M=95.6 \mathrm{mg} / \mathrm{ml})$, in comparison with the group with TSH in the reference interval $(M=68.9 \mathrm{mg} / \mathrm{ml})$ or with TSH $>3.67 \mathrm{mU} / \mathrm{l}(M=62.1 \mathrm{mg} / \mathrm{ml})$. Differences between the normal and raised TSH groups in hCG levels were not significant at $P<0.050$. The other authors confirm that sub-normal serum TSH levels in the first trimester are coincident with rising hCG levels (32).

Differences in anti-TPO Ab manufacturer's reference interval are not comparable from 0.5 to $100 \mathrm{kU} / \mathrm{l}(25$, $27,33,34)$. Reference intervals for thyroid antibody tests should be by the NACB recommendation: established from young male subjects, free from any history of thyroid disease or predisposition for any autoimmune disease (17). Establishment of decision values for

Table 3 Cut-off of anti-TPO antibody for non-selected (NS) and selected (S2) groups of pregnant women.

\begin{tabular}{lccccccc}
\hline Anti-TPO $(\mathrm{kU} / \mathrm{l})$ & $\boldsymbol{N}$ & Median & Minimum & Maximum & $\begin{array}{c}\text { 5th } \\
\text { percentile }\end{array}$ & $\begin{array}{c}\text { 95th } \\
\text { percentile }\end{array}$ & $\begin{array}{c}\text { 90th } \\
\text { percentile }\end{array}$ \\
\hline NS & 5520 & 38 & 0 & 15000 & 8 & 908 & 196 \\
S2 & 5281 & 37 & 0 & 15000 & 8 & 577 & 143 \\
\hline
\end{tabular}

S2, pregnant women with no history of thyroid disease and with TSH level between 0.06 and $3.67 \mathrm{mU} / \mathrm{l}$. 
Table 4 Mean level of free $\beta$ hCG in groups of pregnant women with different concentrations of TSH. Post hoc P-levels for the Tukey honest significant difference (HSD) at $P<0.05$.

\begin{tabular}{|c|c|c|c|}
\hline $\begin{array}{l}\text { Free } \boldsymbol{\beta} \text { hCG }(\mathrm{mg} / \mathrm{ml}) \\
\text { TSH }(\mathrm{mU} / \mathrm{l})\end{array}$ & $\begin{array}{c}M=95.6 \\
\text { TSH }<0.06\end{array}$ & $\begin{array}{c}M=68.9 \\
\text { TSH 0.06-3.67 }\end{array}$ & $\begin{array}{c}M=62.1 \\
\mathrm{TSH}>3.67\end{array}$ \\
\hline$M=95.6 \mathrm{TSH}<0.06$ & & 0.0013 & 0.0010 \\
\hline $\begin{array}{c}M=68.9 \mathrm{TSH} \\
0.06-3.67\end{array}$ & 0.0013 & & 0.4733 \\
\hline$M=62.1 \mathrm{TSH}>3.67$ & 0.0010 & 0.4733 & \\
\hline
\end{tabular}

$\mathrm{M}$, mean free $\beta \mathrm{hCG}(\mathrm{mg} / \mathrm{ml})$.

thyroid antibodies in the healthy population is difficult and results are method dependent (35). The decision value for positivity of anti-TPO was, under our conditions, calculated at the 90th and 95th percentiles. For the first trimester, we used the 90th percentile for the specific reference interval from the selected group S2, and determined a $143 \mathrm{kU} / \mathrm{l}$ anti-TPO (similar to the positivity decision value).

Thyroid hormone's reference intervals for different methods and manufacturers may vary, mostly for FT4 (36). They have been established using pools of nonpregnant normal sera and with different antibodies. FT4 levels fit a Gaussian distribution, so reference intervals were derived using non-parametric analyses such as the 95th percentile. The calculated reference interval 9.55-23.0 pmol/l was very similar to the manufacturer's interval of $9.8-23.1 \mathrm{pmol} / \mathrm{l}$. Despite some authors recommended specific reference interval for pregnancy $(9,26,27)$, we used the producer's. There were $30(4.3 \%)$ women with FT4 under and $18(2.5 \%)$ women with FT4 over the reference interval. In women with low FT4, 62.7\% were with positive anti-TPO antibodies.

In the group of 5520 women, $163(2.93 \%)$ had their TSH under the reference interval $(<0.06 \mathrm{mU} / \mathrm{l})$. The prevalence of hyperthyreosis in pregnant women is $1.7 \%$, and $0.4 \%$ of these women had an elevated serum FT4 level (1). This is similar to that reported for nonpregnant individuals (34). Suppressed serum TSH concentrations during gestation follow hyperthyroidism as well as hyperemesis gravidarum or high hCG levels (9).

Many authors have determined the prevalence of hypothyreosis (overt and subclinical) in pregnancy $(25$, 37 ). The prevalence of hypothyroidism during pregnancy is estimated to be $0.3-0.5 \%$ for overt hypothyroidism and $2-3 \%$ for subclinical hypothyroidism (9). In our study, there were $4.5 \%$ of pregnant women with TSH over our reference limit ( $>3.67 \mathrm{mU} / \mathrm{l})$, which is in concordance with previous hypotheses, as well as with Haddow (2004) who used their own reference interval, identifing $4.3 \%$ of pregnant women with high TSH levels (25).

There exists a positive association between the presence of thyroid antibodies and pregnancy loss with post partum thyroiditis. The positivity of anti-TPO in non-pregnant individuals is about $11 \%(34)$; in the pregnant population it is very similar. Negro (2006) mentioned $11.7 \%$ anti-TPO positive pregnant women (33); Dossiou (2008) selected groups by age and the positivity was 10.4 and 12.6 for ages 25 and 35 years respectively (21). When we used the reference interval recommended by the producer of reagents $(>60 \mathrm{kU} / \mathrm{l})$, we had $22.1 \%$ positivity. If we use the 90th percentile (143 kU/l) as the cut-off for our group of pregnant women, we had $11.2 \%$ positivity. These results correlate very well with other studies. Pregnant women with anti-TPO between 60 and $143 \mathrm{kU} / \mathrm{l}$ were given notice to visit an endocrinologist after delivery; women who had anti TPO $>143 \mathrm{kU} / \mathrm{l}$ were invited to do so immediately.

It is known that women with a high level of TSH more frequently have positive anti-TPO antibodies (33). In our study group, when divided by serum TSH concentration, $44.1 \%$ were anti-TPO positive with TSH $>3.67 \mathrm{mU} / \mathrm{l}$. However, $10.1 \%$ were anti-TPO positive in the part with TSH lower than $0.06 \mathrm{mU} / \mathrm{l}$ and $9.1 \%$ with TSH in the reference interval (0.06-3.67 mU/l).

The greater the pregnant women's age is very often a reference risk factor of thyroid malfunction (31). Stricker (2007) published that the anti-TPO level was related to maternal age (38). Negro (2006) presented a higher prevalence of anti-TPO positivity in older women (33), and the NHANES III study (34) shows slightly increasing levels of TSH and anti-TPO with age. In contrast to these, in our study, we did not find a significant $(P<0.05)$ difference between the average age of the pregnant women with positive anti-TPO and those with low TSH (or in the reference interval). There is also no significant $(P<0.05)$ difference in TSH or anti-TPO concentration in groups, separated by age. It is possible that this is because $76 \%$ of our pregnant women were within the ages of 25-35.

An answer to the question of screening costeffectiveness of thyroid function in pregnancy was already presented by Dosiou (21). Screening would result in an early diagnosis and treatment of thyroid disease, and it is possible to combine it with first trimester screening for Down's syndrome.

In our group of 5520 women, we determined the TSH reference interval to be $0.06-3.67 \mathrm{mU} / \mathrm{l}$. A raised concentration of TSH was found in $4.48 \%$ of women and a suppression of TSH was found in $2.93 \%$ of women. The limit for anti-TPO positivity was determined to be $143 \mathrm{kU} / \mathrm{l}$ and $11.2 \%$ of pregnant women were found to be positive. In the entire group, there was no significant $(P<0.05)$ difference in TSH or anti-TPO concentration in the groups, separated by age.

Systematic cooperation among gynaecologists, endocrinologists, general practitioners, midwives and laboratories should be established in order to solve the problems such as laboratory normal interval, pregnancy timing for examination, unification of diagnostic procedures and the correct interpretation of the results. 


\section{Declaration of interest}

The authors declare that there is no conflict of interest that could be perceived as prejudicing the impartiality of the research reported.

\section{Funding}

This study was supported by Research Project of the Czech Ministry of Education 0021620807.

\section{Acknowledgements}

The authors are grateful to the technicians from the Institute of Clinical Biochemistry and Laboratory Diagnostics Charles University, Prague, Czech Republic for their support.

\section{References}

1 Casey BM, Dashe JS, Wells CE, McIntire DD, Leveno KJ \& Cunningham FG. Subclinical hyperthyroidism and pregnancy outcomes. Obstetrics and Gynecology 2006107 337-341.

2 Lazarus JH. Epidemiology and prevention of thyroid disease in pregnancy. Thyroid $200212861-865$.

3 Lazarus JH \& Premawardhana LD. Screening for thyroid disease in pregnancy. Journal of Clinical Pathology $2005 \mathbf{5 8}$ 449-452.

4 Poppe K, Velkeniers B \& Glinoer D. Thyroid disease in female reproduction. Clinical Endocrinology 200766 309-321.

5 Haddow JE, Palomaki GE, Allan WC, Williams JR, Knight GJ, Gagnon J, O’Heir CE, Mitchel ML, Hermos RJ, Waisbren SE, Faix JD \& Klein RZ. Maternal thyroid deficiency during pregnancy and subsequent neuropsychological development of the child. New England Journal of Medicine 1999341 549-555.

6 Smallridge RC \& Ladenson PW. Hypothyroidism in pregnancy: consequences to neonatal health. Journal of Clinical Endocrinology and Metabolism $2001862349-2353$.

7 Klein RZ, Sargent JD \& Larsen PR. Relation of severity of maternal hypothyroidism to cognitive development of offspring. Journal of Medical Screening 2001 8 18-20.

8 Idris I, Srinivasan R, Simm A \& Page RC. Maternal hypothyroidism in early and late gestation: effect on neonatal and obstetric outcome. Clinical Endocrinology 200563 560-565.

9 Abalovich M, Amino N, Barbour LA, Cobin RH, De Groot LJ, Glinoer D, Mandel SJ \& Stagnaro-Green A. Management of thyroid dysfunction during pregnancy and post partum: an endocrine society clinical practice guideline. Journal of Clinical Endocrinology and Metabolism 200792 S1-S47.

10 Morreale de Escobar G, Obregon MJ \& Escobar del Rey F. Role of thyroid hormone during early brain development. European Journal of Endocrinology $200415125-37$.

11 Mitchell ML \& Klein RZ. The sequellae of untreated maternal hypothyroidism. European Journal of Endocrinology $2004 \mathbf{1 5 1}$ U45-U48.

12 Pop VJ, Brouwers EP, Vader HL, Vulsma T, van Baar AL \& de Vijlder JJ. Maternal hypothyroxinemia during pregnancy and subsequent child development: a 3-year follow-up study. Clinical Endocrinology 200359 282-288.

13 Zimmermann M \& Delange F. Iodine supplementation of pregnant women in Europe: a review and recommendations. European Journal of Clinical Nutrition 200458 979-984.

14 Dayan CM, Saravanan P \& Bayly G. Whose normal thyroid function is better-yours or mine? Lancet $2002360353-354$.

15 Goodwin TM, Montoro M, Mestman JH, Pekary AE \& Hershman JM. The role of chorionic gonadotropin in transient hyperthyroidism of hyperemesis gravidarum. Journal of Clinical Endocrinology and Metabolism 199275 1333-1337.

16 Glinoer D, De Nayer P, Delange F, Lemone M, Toppet V, Spehl M, Grün JP, Kinthaert J \& Lejeune B. A randomized trial for the treatment of mild iodine deficiency during pregnancy: maternal and neonatal effects. Journal of Clinical Endocrinology and Metabolism $1995 \mathbf{8 0} 258-269$.

17 Demers LM \& Spencer CA. Laboratory medicine practice guidelines: laboratory support for the diagnosis and monitoring of thyroid disease. Clinical Endocrinology 200358 138-140.

18 Marai I, Carp H, Shai S, Shabo R, Fishman G \& Shoenfeld Y. Autoantibody panel screening in recurrent miscarriages. American Journal of Reproductive Immunology 200451 235-240.

19 Premawardhana LD, Parkes AB, John R, Harris B \& Lazarus JH. Thyroid peroxidase antibodies in early pregnancy: utility for prediction of post partum thyroid dysfunction and implications for screening. Thyroid $200414610-615$.

20 Nicholson WK, Robinson KA \& Smallridge RC. Prevalence of post partum thyroid dysfunction: a quantitative review. Thyroid 2006 16 573-582.

21 Dosiou C, Sanders GD, Araki SS \& Crapo LM. Screening pregnant women for autoimmune thyroid disease: a costeffectiveness analysis. European Journal of Endocrinology 2008 158 841-851.

22 Zamrazil V, Bilek R, Cerovska J \& Delange F. The elimination of iodine deficiency in the Czech Republic: the steps toward success. Thyroid 200414 49-56.

23 Solberg HE. The IFCC recommendation on estimation of reference intervals. The RefVal program. Clinical Chemistry and Laboratory Medicine 200442 710-714.

24 Ceriotti F. Prerequisites for use of common reference intervals. The Clinical Biochemist. Reviews 200728 115-121.

25 Haddow JE, Knight GJ, Palomaki GE, McClain MR \& Pulkkinen AJ. The reference range and within-person variability of thyroid stimulating hormone during the first and second trimesters of pregnancy. Journal of Medical Screening 200411 170-174.

26 Vaidya B, Anthony S, Bilous M, Shields B, Drury J \& Hutchison S. Detection of thyroid dysfunction in early pregnancy: Universal screening or targeted high risk case finding? Journal of Clinical Endocrinology and Metabolism 200792 203-207.

27 Marwaha RK, Chopra S, Gopalakrishnan S, Sharma B, Kanwar RS, Sastry A \& Singh S. Establishment of reference range for thyroid hormones in normal pregnant Indian women. BJOG : an International Journal of Obstetrics and Gynaecology 2008 115 602-606.

28 Stricker R, Echenard M, Eberhart R, Chevailler MC, Perez V, Quinn FA \& Stricker R. Evaluation of maternal thyroid function during pregnancy: the importance of using gestational agespecific reference intervals. European Journal of Endocrinology 2007 157 509-514.

29 Soldin OP, Tractenberg RE, Hollowell JG, Jonklaas J, Janicic N \& Soldin SJ. Trimester-specific changes in maternal thyroid hormone, thyrotropin, and thyroglobulin concentrations during gestation: trends and associations across trimesters in iodine sufficiency. Thyroid 200414 1084-1091.

30 Soldin OP, Soldin D \& Sastoque M. Gestation specific thyroxine and thyroid stimulating hormone levels in the US and worldwide. Therapeutic Drug Monitoring 200729 553-559.

31 Dashe JS, Casey BM, Wells CE, McIntire DD, Byrd EW, Leveno KJ \& Cunningham FG. Thyroid-stimulating hormone in singleton and twin pregnancy: importance of gestational age-specific reference ranges. Obstetrics and Gynecology $2005 \mathbf{1 0 6}$ 753-757.

32 Surks MI, Ortiz E, Daniels GH, Sawin CT, Col NF, Cobin RH, Franklyn JA, Hershman JM, Burman KD, Denke MA, Gorman C, Cooper RS \& Weissman NJ. Subclinical thyroid disease: scientific review and guidelines for diagnosis and management. Journal of the American Medical Association 2004 291 228-238.

33 Negro R, Formoso G, Mangieri T, Pezzarossa A, Dazzi D \& Hassan H. Levothyroxine treatment in euthyroid pregnant women with autoimmune thyroid disease: effects on obstetrical complications. Journal of Clinical Endocrinology and Metabolism 200691 2587-2591 
34 Hollowell JG, Staehling NW, Flanders S, Hannon WH, Gunter EQ, Spencer CA \& Braverman LE. Serum TSH, T4, and thyroid antibodies in the US population (1988-1994): National Health and Nutrition Examination Survey (NHANES III). Journal of Clinical Endocrinology and Metabolism 200287 489-499.

35 Jensen EA, Petersen PH, Blaabjerg O, Hansen PS, Brix TH \& Hegedüs L. Establishment of reference distributions and decision values for thyroid antibodies against thyroid peroxidase (TPOAb), thyroglobulin ( $\mathrm{TgAb})$ and the thyrotropin receptor (TRAb). Clinical Chemistry and Laboratory Medicine $2006 \mathbf{4 4}$ 991-998.
36 d'Herbomez M, Forzy G, Gasser F, Massart C, Beaudonnet A \& Sapin R. Clinical evaluation of nine free thyroxine assays: persistent problems in particular populations. Clinical Chemistry and Laboratory Medicine 200341 942-947.

37 Lazarus JH. Treatment of hyper and hypothyroidism in pregnancy. Journal of Endocrinological Investigation 199316 391-396.

Received 18 February 2009

Accepted 19 February 2009 